\title{
Blas de Otero: del existencialismo a la poesía social
}

\author{
Blas de Otero: from existentialism to social poetry
}

Cristhian Sarango ${ }^{1}$

\section{Resumen}

Este trabajo ha analizado la evolución de la poética de Blas de Otero. Para ello fue considerado que, en su poética opera una dualidad altisonante: desde uno de los imaginarios es uno de los poetas más leídos de la historia reciente de España y, sin embargo, el otrora de la crítica lo desdeña por la politización de su obra; en su polivalencia la poesía oteriana es tensión existencial, en su primera etapa, y una evidente preocupación social; en la segunda, Blas de Otero es un poeta de conceptos, en particular de contenido social, porque su poesía temprana revela el desgarramiento humano frente al sufrimiento y la angustia existencial del hombre de posguerra. Su evolución como poeta parte de sus inquietudes religiosas y de fe, pasando por el existencialismo, hasta llegar al contenido social. Los textos analizados en este trabajo son una muestra de esa evolución temática en etapas distintas de la producción literaria del autor: "Estos sonetos míos", Ángel fieramente humano (1950) y "Fidelidad”, Pido la paz y la palabra (1955).

Palabras clave: Blas de Otero; existencialismo; Estos sonetos míos; social; Pido la paz y la palabra.

\section{Summary}

This work has analyzed the evolution of Blas de Otero poetics. For this it was considered that, in his poetry, a high-sounding duality operates: from one of the imaginary he is one of the most read poets in the recent history of Spain and, nevertheless, the former criticism disdains him for the politicization of his work; in its versatility oterian poetry is existential tension, in its first stage, and an evident social concern; in the second. Blas de Otero is a poet of concepts, in particular of social content, because his early poetry reveals the human tear in the face of the suffering and existential anguish of post - war man. His evolution as a poet starts from his religious and faith concerns, going through existentialism, until reaching the social content. The texts analyzed in this work are a sample of this thematic evolution in different stages of the author's literary production: "These sonnets of mine", Angel fiercely human (1950) and "Fidelity", I ask for peace and the right to talk (1955).

1 Doctorando en el Programa en Filología. Máster en Literatura Española por la Universidad de Barcelona, Docente investigador de la Sección Lenguas Hispánicas y Literarias de la Universidad Técnica Particular de Loja, Ecuador. Correo: cgsarango@utpl.edu.ec ORCID: http://orcid.org/oooo-0003-1303-7702

Recibido: 11/02/2020 Aprobado: 29/05/2020

Sarango, C. (2020). Blas de Otero: del existencialismo a la poesía social. Ciencia E Interculturalidad, 26(01), 108-114. https://doi.org/10.5377/ rci.v26i01.9888 
Keywords: Blas de Otero; existentialism; These sonnets of mine; social data; I ask for peace and the right to talk.

\section{Introducción}

En el presente estudio, por medio de un ejercicio crítico, se propone analizar los poemas: "Estos sonetos míos" del libro Ángel fieramente humano (1950) y "Fidelidad" del libro Pido la paz y la palabra (1955).

En el primer poema citado, vemos esa relación entre la existencia y el hombre. "Ese paseo rocambolesco de la poesía. La tiranía de los versos. Asimismo, el fracaso de la vida. El retorno del llanto por un Dios perdido. El eterno frenesí erróneo de la muerte" (Sarango, 2018, pág. 3). Además, la posibilidad de engaño y desengaño. Por otro lado, en el segundo poema mencionado, según el criterio de García Montero (2004) "El autor, la fecha y el título parecen sugerirnos que se trata de una respuesta circunstancial a la falta de libertad en la España franquista y a las secuelas ideológicas de la Guerra Civil y de la II Guerra Mundial".

Por lo tanto, nuestro objetivo es estudiar la transformación histórica de la poética de Blas de Otero, concretamente en dos poemas: "Estos sonetos míos", Ángel fieramente humano (1950) y "Fidelidad", Pido la paz y la palabra (1955). En esta relación dicotómica, trataremos de examinar la transformación de un tipo de poesía existencialista e idealista a una de carácter social, en donde el autor busca representar a la sociedad española en sus letras.

\section{Desarrollo}

La influencia de la tradición sonetista del Siglo de Oro, de Garcilaso, Lope, Góngora y Quevedo se manifiesta en la selección estrófica de "Estos sonetos míos" cuya composición responde a estructuras clásicas del soneto y que caracterizará a la poesía de esta primera etapa. Esta preferencia estrófica la justifica Otero en su poema "Su íntimo secreto", cuando dice que "El soneto es el rey de los decires" (Otero, 2013). En consecuencia, el texto analizado está compuesto por 14 versos endecasílabos divididos en dos cuartetos y dos tercetos, con rima consonante $A B B A, A B B A, C D C, D C D$.

En el primer cuarteto, aparecen algunas metáforas para hablar sobre sus versos: los llama "plumas de luz" (v. 2) y "cárceles de mi sueño", y recurre a la antítesis "ardiente río" (v. 3) para expresar la contradicción interna de la que parte su cantar. Dice que en su literatura anega su angustia de ser humano.

En el segundo cuarteto, la voz poética se confiesa desamparada y agónica, en un "palpar de ciego" (v. 8), ante el silencio de Dios frente a las preguntas contenidas en sus versos, aquí "el amor divino se manifiesta como silencio" (Ascunce Arrieta, 1990, 


\section{CIENCIAS SOCIALES}

p. 60), lo que produce la angustia existencial. Nuevamente define su poesía como un "vacío silencio" (vv. 6-7) y la compara con un "yerto mar" (v. 7). También encontramos un encabalgamiento (vv. 6-7) que se convertirá en un recurso característico del estilo de Blas de Otero.

En el primer terceto llama a su canto "Manos de Dios" (v. 9); son manos que llegan a lo más profundo de su padecimiento, a la muerte, a "donde el alma se hace llanto" (v. 10). Aparece aquí el tema del hombre como ser destinado a la muerte, únicamente salvado por la poesía. Y termina el terceto con una anadiplosis "Verte un momento, oh Dios, después no verte" (v. 11) con la que manifiesta la angustia humana frente a un Dios esquivo, al que se dirige a través de un apóstrofe.

Finalmente, en el segundo terceto se refiere a sus versos como "llambria" y "cantil" (v. 12), es decir, que son un borde, un límite del que el poeta se sostiene para no sucumbir frente a la soledad. De nuevo encontramos un encabalgamiento (vv.12-13) y otra antítesis (v. 13), para referirse a su poesía: "ciega luz". El soneto concluye con la explicación del sentido de su arte: "Quiero tenerte/ y no sé dónde estás, por eso canto" (vv. 13-14).

En su segunda etapa Blas de Otero busca en un estilo coloquial, dejando de lado la rigurosidad clasicista de los sonetos y prefiriendo el verso libre, sus poemas se vuelven realmente sencillos "por eliminación de elementos" (Montejo Gurruchaga, 1988, p. 26). "Fidelidad" está compuesto por 16 versos, la mayoría, endecasílabos, alternados con versos libres. La rima es asonante en "o" a lo largo de todo el poema. Internamente, se divide en tres partes marcadas por la anáfora y un tono narrativo-descriptivo: la primera parte está comprendida entre los versos 1 y 5 y pone de manifiesto la experiencia de la voz poética en la guerra. Al decir "he visto" nos anticipa el uso de la imagen que se desarrolla en estos primeros versos, gracias a la metonimia: "espaldas astilladas" (v. 2), "almas cegadas" (v. 3). Con el uso del plural "españas" hace referencia a la experiencia de ver cómo su país se dividía en dos bandos durante la Guerra Civil.

La segunda parte la constituyen los versos del 6 al 10, en los que el yo lírico mantiene vivas sus ansias de paz a pesar del sufrimiento pasado. El verso 6 tiene un paralelismo sintáctico con el verso 1 , con la anáfora se reitera la fe del poeta, esta vez en la paz. En estos versos se utiliza la imagen y el simbolismo: las altas estrellas, los "llameantes ámbitos amanecientes/incendiando ríos hondos" (vv. 7-8). Nuevamente aparece el recurso de encabalgamiento y también la antítesis "incendiando ríos", que recuerda al "ardiente río" del poema "Estos sonetos míos". La metáfora "caudal humano hacia otra luz" hace referencia a la muerte de los hombres y, termina la sección con la reiteración "he visto y he creído" (v. 10).

La tercera y última parte abarca los versos del 11 al 16, en los que se expresa la confianza en una España mejor. En el primer verso de esta sección se repiten las palabras 
"Creo en", sin embargo, no hay paralelismo porque el verso termina con "digo". Esta palabra expresa la voluntad del yo poético de hablar, de decir, su necesidad de no callar lo que ha visto. Utiliza una metáfora y un encabalgamiento en "relámpagos de rabia" (vv. 12-13), una personificación y otro encabalgamiento en "un cuchillo chillando" (vv. 13-14), estos recursos le sirven para transmitir la idea de odio y de violencia. El cuchillo está "haciéndose pedazos de pan" (vv. 14-15); es decir, la violencia se convierte en el único alimento posible durante la guerra, la gente queda empobrecida y hambrienta. Los últimos versos hablan sobre la terrible situación de la patria "aunque hoy hay solo sombra" (v. 15) se crea un contraste con la reiteración con la que se cierra el poema "he visto y he creído" (v. 16).

En general, en el plano morfosintáctico, se halla en este texto abundantes sustantivos (dolor, hambre, ríos...) y verbos tanto en presente (creo, digo) como en pretérito perfecto compuesto (he visto, he creído) que corroboran el tono reflexivo de Blas de Otero ante los acontecimientos presentados. En el plano léxico-semántico, además de las figuras señaladas, podemos ver que las palabras utilizadas corresponden a un campo semántico vinculado con la guerra (trallazos, dolor, hambre, rabia, cuchillo). En el plano fonético-fonológico es importante remarcar la aliteración en " $r$ " en "rabia, dolor, ríos" para mostrar la agresividad del conflicto bélico.

\section{Un universo de sentidos}

"Estos sonetos míos", corresponde a una primera fase de formación, en la que se concentra poesía oteriana más marcadamente existencial. Esta etapa está asociada con los años de vida del autor comprendidos entre 1944 y 1955, años críticos porque están marcados por una crisis depresiva que le lleva a una profunda transformación en la que sus creencias y su fe se resquebrajan y "el diálogo con el Ser Supremo se interrumpe, entrando en una noche oscura del alma larga y dolorosa, donde no se vislumbra salida posible ni se encuentra solución viable" (Ascunce Arrieta, 1990, p. 59). Esta crisis le lleva a buscar una nueva razón para la existencia del hombre: el amor y la poesía. Ángel fieramente humano es la expresión de la poesía desarraigada: Blas de Otero se rebela como hombre ante el sufrimiento de sus congéneres, su soledad es una crónica de lucha contra el poder y la desesperanza, los tópicos que recorren esta obra son el amor, la mortalidad del hombre y la angustia. Allí "se desarrolla una lucha feroz de amor y de rechazo entre sus dos protagonistas, Dios y el poeta" (Cruz, S. y Montejo, L., 1995, p. XXI).

Así, la búsqueda que se lleva a cabo es la respuesta estética a una razón existencial (Ascunce Arrieta, 1990, p. 80), un desapego definitivo a la forma de la esperanza como emblema de la poesía religiosa, hacia una trasformación en esperanza fallida, una búsqueda sin encuentro. El soneto oteriano rezuma humanidad precisamente por el descubrimiento de su campaña frustrada. Sólo queda lo que da el humano en sí y 


\section{CIENCIAS SOCIALES}

para sí; la angustia de su existir, la ceguera ante lo divino, tan lejos de su condición, y el canto desesperanzado ante la certeza de la soledad absoluta.

En síntesis, "Estos sonetos míos" es un claro ejemplo de una primera etapa poética de Blas de Otero caracterizada por el desarrollo de temas relacionados con la angustia existencial del hombre frente a la muerte y a la ausencia de Dios, y la posibilidad de salvación a través del amor y de la poesía.

Por su lado, "Fidelidad" se enmarca en período vital del autor (1955-1964) y corresponde a una etapa de poesía social, más interesada en el colectivo y sus circunstancias, en la solidaridad como posibilidad de salvación: en un "humanismo utópico" (Ascunce Arrieta, 1990, p. 83) y en un historicismo revolucionario. La tragedia personal y existencialista se diluye en el dolor colectivo de "la inmensa mayoría", como señala en su dedicatoria, evidenciando que la obra ha sido escrita desde la fraternidad con los oprimidos, con espíritu combativo y que las preocupaciones sobre Dios han dado paso al interés en lo humano. El título del poema es ya de por sí muy sugestivo: "Fidelidad" y nos lleva a preguntarnos: fidelidad ¿a quién? a sus convicciones, a su esperanza en el hombre, a la paz y a la patria; fidelidad a su capacidad para creer a pesar de todo lo que ha visto.

Este poema constituye un credo del poeta en lo humano, más que en lo divino; pero, también de fe en su nación a pesar de la guerra y del desgarramiento. Al intentar publicar esta obra, Blas de Otero tropezó "con la prohibición de la censura: la palabra ha de ser enmascarada, la paz se [había] convertido en un vocablo subversivo” (Montejo Gurruchaga, 1988, p.15).

Por esta razón, abundan en sus versos las metáforas y las imágenes literarias, como la que se encuentran en "Fidelidad": "He visto/ altas estrellas, llameantes ámbitos / amanecientes, incendiando ríos / hondos, caudal humano / hacia otra luz" (vv. 6-10), para hacer referencia a la esperanza de un cambio, de un futuro mejor, pues Blas de Otero, "nacido y formado en el período de entreguerras pide la paz para una patria que sigue perpetuando el recuerdo de la guerra. Y si antes se había debatido en el silencio y la oscuridad, ahora resurge a una nueva fe" (Montejo Gurruchaga, 1988, p. 26). Esta fe le viene de sus experiencias. En el poema aparecen las afirmaciones "he visto" y "he creído", repetidas veces, enfatizando así su propia experiencia y justificando por qué cree en lo que escribe. La protesta contra el sufrimiento y la esperanza en la solidaridad humana es el tema central de la obra Pido la paz y la palabra.

Entre 1960 y 1964 Blas de Otero realizó largos viajes "a los países donde ha triunfado la revolución socialista" y los poemas que escribe durante su viaje son "un intento de retener [a España] en su memoria” (Montejo Gurruchaga, 1988, p. 27). Esto prueba el apego que sentía el poeta por su patria. Por eso, "el tema personal se funde con el 
tema histórico [y la palabra es] el único medio de salvación para el poeta y el pueblo" (Montejo Gurruchaga, 1988, p. 25).

A través de estos dos poemas, vemos cómo la obra Blas de Otero parte de una reflexión personal, de una crisis existencial individual, caracterizada por la angustia, la soledad frente a Dios y su silencio, hacia una poesía de esperanza y de fe en el ser humano más que en el aspecto divino. En los dos poemas encontramos similitudes en cuanto al estilo y al uso de metáforas, imágenes y encabalgamientos, pero con una evolución hacia versos más libres y formas estróficas menos tradicionales.

El tránsito vivido por Otero en su vida se refleja claramente en su obra: el poeta se halla inmerso en el propio devenir personal que se hace evidente en la progresiva madurez de su poética. Pasa de un estado existencial, y por tanto más individual, a una postura más social en la que el colectivo encarna su preocupación; la política aparece en el horizonte y la interrogante canónica aparece: “¿Cuál es la verdadera magnitud de un poeta que es ensalzado, por algunos, antes por su militancia política que por su creación poética?" (Parada Rodríguez, 2013, p. 3).

Y la respuesta es clara frente a una interrogante de esta naturaleza en la obra oteriana: Blas de Otero es, ante todo, un poeta no un militante; poniendo en perspectiva el general de su obra, es relevante la preocupación del poeta por la forma propia de la poesía no de su mensaje, que queda a interpretación libre del lector. Es una muestra de la estética que supera a la simple comunicación de unas ideas.

\section{Conclusiones}

En conclusión, la obra de Blas de Otero marca una tendencia significativa en la poesía en español, retomando las huellas dejadas por otros antes que él, y descubriendo la madurez en la forma precisa y original, enmarcada en el salto ontológico del ser individual al ser social. Además, en "Estos sonetos míos" del libro Ángel fieramente humano (1950) representa la caracterización del elemento humano con la búsqueda de un Dios supremo. Por el contrario, "Fidelidad" del poemario Pido la paz y la palabra (1955) simboliza la caracterización de la humanidad con el dolor y la muerte de una España sumergida en plena guerra civil.

\section{Agradecimiento}

Esta publicación obtuvo el financiamiento de: El Fondo de Asistencia Internacional de los Estudiantes y Académicos Noruegos (SAIH).

\section{Lista de referencia}

Alonso, D. (1965). Poetas españoles contemporáneos. Madrid: Gredos. pp. 345-349. 


\section{CIENCIAS SOCIALES}

Ascunce Arrieta, J. Á. (1993). "Ética y estética en la poesía de Blas de Otero" en Ojáncano (Athens, GA), No. 8, pp. 3-28.

Azaola, J. M. de (1989). "Blas de Otero, amigo fieramente humano" en Pérgola, Revista Cultural (Bilbao), n. ${ }^{\circ} 16$ (diciembre de 1989), pp. 45-66.

Bengoechea, J. de (1990). "Blas de Otero y la poesía social” en Zurgai, monográfico Poetas vascos (diciembre de 1990), pp. 53-54.

García de la Concha, V. (1987). "Blas de Otero: Contra el silencio de Dios. A la inmensa mayoría: Ancia” en La poesía española de 1935 a 1975. II: De la poesía existencial a la poesía social 1944-195, Madrid, Cátedra, pp. 539-559.

García Montero, L. (2004). Reflexiones junto a Blas de Otero.

Lanz, J. J. (ed.) (2008). Alas de cadenas. Estudios sobre Blas de Otero, Sevilla: Renacimiento.

López Abiada, J. M. (1999). “Hombre' y 'A la inmensa mayoría', de Blas de Otero”, en López de Abiada, J. M. et al. Poemas memorables. Antología consultada y comentada (1939-1999), Madrid, Castalia, pp. 83-93.

Montejo Gurruchaga, L. (1988). Teoría poética a través de la obra de Blas de Otero. Madrid: Universidad Complutense de Madrid.

Parada Rodríguez, J.L. (2013). La esperanza en Blas de Otero. Tesis doctoral. Madrid: Universidad Francisco de Victoria. [Documento ON LINE]. Recuperado de: http://ddfv.ufv.es/bitstream/handle/10641/907/La\%20Esperanza\%20 en\%2oBlas\%2ode \%20Otero\%20-\%20Tesis\%2oDoctoral\%20J.L.\%2oParada. pdf? sequence $=1$.

Pedraza Jiménez, Felipe Blas y Milagros Rodríguez Cáceres (1981). Manual de literatura española, Cénlit, Tafalla (Navarra).

Sarango, C. (2018). Análisis comparativo de dos poemas de Miguel de Unamuno: Id con dios y la Oración del ateo.

Soler, F. M. (2017). Poesía de Blas de Otero. Mis comentarios. Sur: Revista de literatura, (10), 8 .

Terrasson, C. (2011). Blas de Otero:' ¿Poeta de la condición humana y de su desamparo?'. Cauce, 2011-2012, (34-35): 407-426.

Vilanova, A. (1998). La poesía española del 98 a la posguerra, Barcelona: Lumen. 